\title{
The Effect of Communication on Employee Brand Understanding, Brand Commitment, and Brand Citizenship Behavior: An Abstract
}

\author{
Rico Piehler, Michael Schade, and Christoph Burmann
}

\begin{abstract}
Because employees are important for building and maintaining brandcustomer relationships, managing employee behavior in applying internal brand management (IBM) becomes a critical success factor in brand management. As communication is one of the most powerful tools of organizations to inform employees about the brand, to build affective attachment, and to influence employee behavior, this study investigates the effect of internal and external communication on these employee-related IBM outcomes. Based on a sample of 521 employees working in a German service company in the tourism sector, this study validates the positive direct effect of internal communication usage on the cognitive IBM outcome of brand understanding. The effect on the affective IBM outcome of brand commitment is fully mediated by brand understanding. In addition, the effect on the behavioral IBM outcome of brand citizenship behavior is fully mediated by brand understanding and brand commitment. In contrast, external communication congruence had positive direct effects on brand understanding, brand commitment, and brand citizenship behavior. Therefore, our findings especially highlight the oftenoverlooked role of external communication for internal brand management. Overall, the study contributes to literature by integrating marketing research (advertising, services marketing, brand management) and organizational behavior research (organizational identity, organizational commitment/identification, role theory).
\end{abstract}

References Available Upon Request

R. Piehler $(\bowtie) \bullet$ M. Schade $\bullet$ C. Burmann

University of Bremen, Bremen, Germany

e-mail: rico.piehler@uni-bremen.de; mschade@uni-bremen.de; burmann@uni-bremen.de

C) Academy of Marketing Science 2017

P. Rossi (ed.), Marketing at the Confluence between Entertainment and Analytics, Developments in Marketing Science: Proceedings of the Academy of Marketing Science, DOI 10.1007/978-3-319-47331-4_118 